\title{
Teenage suicides in northern Sweden: an interview study of investigating police officers
}

Per Lindqvist, Lars Johansson

\begin{abstract}
Objective-To disclose recurrent, dynamic, and static factors in teenage suicide involving the suicidee, his/her family, and the community; and to investigate the feasibility of using police as informants for suicide studies.

Subjects-All deaths categorised as suicide 1993 through 1995 among teenagers in Northern Sweden $(n=15)$.

Method-Semiqualitative interviews with police officers, and, when applicable, general practitioners. Police reports, necropsy protocols, medical records, and conscription data were also analysed.

Results-Most suicides occurred in rural and depopulated areas. In contrast to males, females often had a history of overt psychiatric problems with suicide attempts. At least two thirds of the suicides were planned.

Conclusion-Cultural and sociopolitical aspects are important in teenage suicide as well as gender differences. Police officers can provide essential information. Identifying teenagers at risk remains difficult, however, due to low baseline rates.

(Injury Prevention 2000;6:115-119)
\end{abstract}

Keywords: teenager; suicide; geographical patterns; interview study

A teenage suicide can be perceived as a forceful denial of the adult world, provoking guilt, anger, anxiety, and infinite sorrow for the involved families, relatives, and friends. ${ }^{1}$ While suicidal ideation is a common feature during adolescence, ${ }^{2}$ possibly constituting a nonpathological and transient phenomenon, completed suicide is an infrequent event among teenagers in Sweden. ${ }^{3}$ Although rates have not been increasing, the number of people affected is considerable. Teenage suicide remains a societal concern because the funeral of a young person is also the burial of a future.

Present research on suicide among young people is somewhat disintegrated theoretically, ${ }^{4}$ targeting particular aspects such as sociological, psychological, or psychiatric risk factors. The complex interaction between individual, family, and societal patterns may benefit from analyses using qualitative methods where several perspectives are simultaneously kept in focus. This may reveal new insights, assisting in enhancing the prevention of teenage suicide.

The aims of this study were to disclose recurrent dynamic and static factors in teenage suicide regarding the suicidee, the family, and the community, and to investigate the feasibility of using police as informants for suicide studies.

\section{Subjects and methods}

The cases were gathered from the catchment area of the Institute of Forensic Medicine in Umeå which covers the four northernmost rural counties of Sweden (population 1994: 924 000). The mean annual suicide incidence among teenagers in northern Sweden was $8 / 100000$ during the study period, which is similar to Sweden as a whole. ${ }^{5}$ According to Swedish law, all cases of unnatural death are to be investigated by police including a forensic medical examination.

All deaths categorised as suicide (E950E959) between 1 January 1993 and 30 May 1995, among individuals aged 13-19 years at the time of their death, were included. Fifteen such cases were identified. No death in this age category was classified as "undetermined manner of death" (E980-E989). A check with the National Cause of Death Register in June 1997 added no further cases.

Police reports, necropsy protocols, medical records from the nearest district medical office, and from child and adolescent psychiatric and paediatric services, were requested. Records from other medical clinics were collected when applicable. The psychological records from the military service were retrieved for males older than 16 years.

As a key informer for each interview we chose police officers who had conducted the investigation of the suicide. When they referred to other police officers, we interviewed them as well. These interviews took place at the police station in or near the community where the suicides had occurred. In seven cases, we visited the site of the suicide as well as the neighbourhood where the suicidee had lived.

We did not contact family members because we thought at that time, that an intrusion in the form of an interview, long after the suicide, would be harmful to the families.

The main purpose of the interviews was to gather information not found in the official reports. Subsequently, we created an informal and confidential interview. Hence, we chose not to use audio or videotapes because they could impede the informant's readiness to present "soft" data. One of us (PL) lead the conversation, while the other (LJ), took notes, supplemented the interview, and ensured that three issues were covered: (a) previous suicide attempts by the suicidee, by other family members, friends, or in the local community; (b) psychiatric morbidity, substance abuse, or antisocial behaviour of the suicidee or in the 
Table 1 Age and gender distribution of teenage suicides in northern Sweden 1993-95

\begin{tabular}{llllllll}
\hline & \multicolumn{2}{c}{ Age (years) } & & & \\
\cline { 2 - 6 } & 14 & 15 & 16 & 17 & 18 & 19 & Total \\
\hline Female & 0 & 1 & 0 & 1 & 2 & 0 & 4 \\
Male & 1 & 0 & 1 & 0 & 4 & 5 & 11 \\
Total & 1 & 1 & 1 & 1 & 6 & 5 & 15 \\
\hline
\end{tabular}

family; and (c) social structure of the local community. Otherwise, the interviews were open and introduced by the question: "What do you think about this?" This inductive approach was chosen to capture information that we did not know to ask for, and also to give the police officer an opportunity to express his thoughts about the case, without being influenced by our questions.

A modified version of Beck's suicide intention scale, originally created to assess suicide risk after suicide attempts, was used to evaluate each suicide case in regards of intent. ${ }^{6}$

The information gathered from the interviews was dictated separately by the authors directly after the interviews. Further reflections were recorded successively. The transcripts were read and re-read thoroughly. As a result of this analysis, we agreed to divide the sample into four subgroups that appeared to be internally consistent as regard gender, family background, psychiatric history, social adjustment, suicide location, and blood alcohol concentration at necropsy. Each group is presented as an aggregated case report.

The study was approved by the Ethical Committee of the Medical Faculty, Umea University.

\section{Results}

Eleven males and four females committed suicide during the period. The age distribution is shown in table 1. Eight were living in the interior parts of the area in communities with less than 10000 inhabitants, five in cities with 10000 to 20000 inhabitants, and two in cities with more than 20000 inhabitants.

\section{SOCIAL SITUATION}

Nine teenagers were raised in their original families and six with divorced parents. All but two had siblings. Eleven of the fathers were blue collar workers, three had white collar jobs or were running small enterprises, and one suicidee lived in a socially high profile family. In 13 of the 15 families at least one of the caretakers had stable employment.

Six boys had been warned by the police for minor offences. Three were known to consume excessive amounts of alcohol and another two were regarded as abusers of both alcohol and illicit drugs. None was, however, categorised as substance dependent or an abuser in the file material.

\section{PSYCHIATRIC HISTORY AND SUICIDE ATTEMPTS}

None of the suicidees was reported to have had a parent who had been treated for a psychiatric disorder or who had committed suicide. In five families the male caretaker was regarded as an alcohol abuser. Four subjects, three of whom were girls, had been voluntarily admitted to inpatient psychiatric care and discharged with the following diagnoses: psychosis, anorexia nervosa, depression, and anxiety neurosis. Another subject had been referred to, but not examined by, a psychiatrist. The five individuals who had made previous suicide attempts had all been referred to psychiatric treatment.

\section{THE SUICIDE ACT}

Four died by hanging, by firearms, and by poisoning, respectively, and two by strangulation. One committed suicide by crashing a car. Six of the 15 subjects tested positive for blood alcohol $(0.029 \%-0.22 \%)$ at necropsy. The eighth subject, who was brought alive to hospital but soon died, was not tested for blood alcohol but according to friends had been drinking before the suicide.

Based on Beck's suicide intention scale, 11 suicides were categorised as planned and four as impulsive (see table 2).

\section{CASE REPORTS}

Female suicide victims brought up in intact and stable families $(n=3)$

These girls grew up in small communities, not far from a city. Their families were described as closely knit but secluded. The parents were working in public service. One of the fathers

Table 2 Suicidal intent in teenage suicide in northern Sweden 1993-95 (modification of Beck's suicide intent scale')

\begin{tabular}{|c|c|c|c|c|c|c|c|c|c|c|c|c|c|c|c|c|}
\hline Case No & 1 & 2 & 3 & 4 & 5 & 6 & 7 & 8 & 9 & 10 & 11 & 12 & 13 & 14 & 15 & Total \\
\hline \multicolumn{17}{|l|}{ Isolation } \\
\hline Someone present & & & & & & & & & & & & & & & & 0 \\
\hline Someone nearby & & & & & & & $\mathrm{X}$ & & & & $\mathrm{x}$ & $\mathrm{X}$ & $\mathrm{x}$ & $\mathrm{X}$ & $\mathrm{X}$ & 6 \\
\hline Alone & $\mathrm{x}$ & $\mathrm{X}$ & $\mathrm{x}$ & $\mathrm{X}$ & $\mathrm{X}$ & $\mathrm{x}$ & & $\mathrm{X}$ & $\mathrm{X}$ & $\mathrm{X}$ & & & & & & 9 \\
\hline \multicolumn{17}{|l|}{ Timing } \\
\hline Intervention possible & & & & & & & $\mathrm{X}$ & & & & $\mathrm{x}$ & $\mathrm{x}$ & $\mathrm{x}$ & $\mathrm{x}$ & $\mathrm{X}$ & 6 \\
\hline Intervention unlikely & $\mathrm{x}$ & $\mathrm{x}$ & $\mathrm{x}$ & $\mathrm{X}$ & $\mathrm{X}$ & $\mathrm{x}$ & & $\mathrm{X}$ & $\mathrm{x}$ & $\mathrm{X}$ & & & & & & 9 \\
\hline \multicolumn{17}{|l|}{ Precautions against discovery } \\
\hline None & & & & & & & $\mathrm{x}$ & & & & $\mathrm{x}$ & & & & $\mathrm{X}$ & 3 \\
\hline Passive & & $\mathrm{X}$ & & & & & & & & & & & & & & \\
\hline Active & $\mathrm{X}$ & & $\mathrm{X}$ & $\mathrm{X}$ & $\mathrm{X}$ & $\mathrm{X}$ & & $\mathrm{X}$ & $\mathrm{X}$ & $\mathrm{X}$ & & $\mathrm{X}$ & $\mathrm{X}$ & $\mathrm{X}$ & & 11 \\
\hline \multicolumn{17}{|l|}{ Planning } \\
\hline No preparations & & & & & & & $\mathrm{X}$ & & & $\mathrm{X}$ & $\mathrm{X}$ & & & & & 3 \\
\hline Minimal/moderate & & & & $\mathrm{X}$ & & & & & $\mathrm{X}$ & & & $\mathrm{X}$ & $\mathrm{x}$ & $\mathrm{X}$ & $\mathrm{X}$ & 6 \\
\hline Extensive & $\mathrm{X}$ & $\mathrm{X}$ & $\mathrm{X}$ & & $\mathrm{X}$ & $\mathrm{X}$ & & $\mathrm{X}$ & & & & & & & & 6 \\
\hline \multicolumn{17}{|l|}{ Suicide note } \\
\hline Yes & $\mathrm{X}$ & $\mathrm{X}$ & $\mathrm{x}$ & & $\mathrm{X}$ & & & $\mathrm{X}$ & & $\mathrm{X}$ & & $\mathrm{X}$ & & & & 7 \\
\hline \multicolumn{17}{|l|}{ Conclusion } \\
\hline Planned & $\mathrm{X}$ & $\mathrm{x}$ & $\mathrm{x}$ & $\mathrm{X}$ & $\mathrm{X}$ & $\mathrm{x}$ & & $\mathrm{X}$ & $\mathrm{X}$ & & & & $\mathrm{x}$ & $\mathrm{X}$ & $\mathrm{X}$ & 11 \\
\hline Impulsive & & & & & & & $\mathrm{X}$ & & & $\mathrm{X}$ & $\mathrm{x}$ & $\mathrm{x}$ & & & & 4 \\
\hline
\end{tabular}


had a disguised alcohol problem. All were living with their families, attending school, and seemed rather talented. None had a drug problem. At least two of the girls had, from early adolescence, expressed suicidal ideation and shown parasuicidal behaviour and psychiatric symptoms. All three had been hospitalised in a psychiatric clinic after a referral from someone outside the families.

The girls were all facing a life crisis at the time of the suicide. One, who had recognised that her boyfriend had dated other girls, committed suicide while her psychotherapist was on holiday. Another girl had recently graduated without future plans. She committed suicide in the psychiatric clinic where she had been admitted four months previously. The third girl looked upon herself as a social failure, in contrast to other family members. A long lasting psychiatric treatment had, on her own request, terminated six months before her death. The suicides were well planned and resolutely carried out. None tested positive for alcohol at necropsy. Although the girls had conveyed suicidal ideation during an extensive period, the timing came as a surprise. All appeared to have improved before the suicide - for example, one with an eating disorder started to eat normally. After the suicide, all the parents refused the professional support that was offered.

\section{Male suicide victims brought up in intact and stable families $(n=4)$}

Three of the boys lived in the inner, depopulated part of the region, and one lived in a suburban part of a major city. Their families were seen as difficult to come to know. Two were seen as informal leaders, one of whom was known by the police for minor offences and heavy drinking on weekends with concomitant aggressive behaviour. None had been subject to psychiatric care, although one had been talking with his general practitioner irregularly about personal problems for some years. The contact was terminated one year before the suicide. None had made suicide attempts or presaged the coming suicide by parasuicidal behaviour except one boy who had told a friend a couple of days before the suicide: "I might as well hang myself", without further elaboration.

All four died at sites where intervention was unlikely. Two tested negative for blood alcohol at necropsy, while the other two were positive $(0.029 \%$ and $0.19 \%)$. The suicides were associated with a broken relationship with a girl (two cases), unemployment (one case), and controversy with the parents regarding schooling (one case). As with the girls brought up in a similar social milieu, the parents declined offers of psychological counselling after the suicide.

Male suicidees brought up in families with common social problems $(n=5)$

These boys were reared in small communities in the vicinity of minor cities inland. Their families had various kinds of common social problems; split families (four cases), criminality among (half) siblings (two cases), and an assaultive, alcoholic father (one case). Two of the five suicidees had no record of alcohol abuse or antisocial behaviour. The others were in the process of becoming delinquents as well as alcohol abusers according to the informants.

All but one of the suicides appeared to be impulsive, after disputes with significant others and a similar proportion had high blood alcohol concentrations at necropsy $(0.13 \%-$ $0.22 \%)$. The fifth had lethal concentrations of phenobarbital in the blood. However, there was time for second thoughts; one prepared a snare with an electric cable, one made arrangements and killed himself with car exhaust in a garage, one intoxicated himself with both licit and illicit drugs, possibly in the company of inebriated friends who did not notice anything particular, and one took his father's firearm and drove some $25 \mathrm{~km}$ before shooting himself. The only carefully prepared suicide concerned a boy who had told a physician that he, one day, could hurt either himself or others. He was referred to a psychiatrist but cancelled the appointment. Two weeks before the suicide his application to a most desired school was turned down, and his peers reported that he subsequently became calm.

\section{Suicidees with a severe, traumatic life history \\ $(n=3)$}

The life histories of two boys and one girl featured severe and ongoing trauma from childhood. Two mothers died before the victim reached school age. Both mothers had been married to alcohol abusing men, one of whom was a violent criminal. The extended families displayed a variety of social and mental deviance: alcoholism, mental retardation, assaultativeness, or child neglect.

Social welfare had early on initiated more or less temporary placements, where, however, the problems continued. One suicidee, for example, was moved to live with a relative, whom the boy found dead by suicide two years before he committed suicide himself. Another suicidee had been a long term inpatient at a psychiatric clinic after moving back and forth between his divorced parents. At the age of 12, he was found in a public place, unconscious due to alcohol ingestion, with semen in his rectum. No case was opened and the matter is sparsely accounted for in the file material. At that time he also made a serious suicide attempt. He was eventually transferred to an institution with limited psychiatric and therapeutic competence where he finally committed suicide. The life history of the third case, a girl, is more obscure. She killed herself in a way strikingly similar to the way her mother died many years before.

These teenagers used violent suicide methods in public places, such as a dump, a men's toilet, and a road. According to our interviews, the triggering events were thought to be a broken love affair, disappointment with a father's relapse in alcoholism, and repeated breaking of promises by a mother. One was sober at the time of the death, one tested positive for blood alcohol $(0.19 \%)$, and one was not tested. 


\section{Discussion}

THE SUICIDEES

Most of the subjects in this study were facing normal life crises like broken love affairs, unemployment, and discord with parents. The majority were neither regarded by laymen as mentally unstable, nor as psychiatric patients at the time of the suicide. This finding differs from many other reports that demonstrate a high prevalence of psychiatric disorders in completed teenage suicide. ${ }^{78}$ The discrepancy may reflect our conservatism in attributing psychiatric diagnoses based on, at best, second hand information. Further, the risk of exaggerating mental abnormality in retrospect is obvious, as a suicide is an appalling event, yearning for an explanation.

The results indicate important gender differences. Almost all boys were successful in concealing their suicidal ideation and did not seek professional advice or support. Yet, it was possible to retrospectively see that subtle and disguised actions had been made to call for attention. Being unable to relate personal problems to others may indicate a lack of ability to reflect, which would explain the stereotypical and conventional suicide notes four wrote. We postulate that boys who can verbalise and relate their difficulties may be less likely to commit suicide.

Most of the girls, on the other hand, did seek professional help and it is remarkable that they did this at an early age and mostly on their own initiative. Their suicidal processes were overt, but by alternating in being anxiety provoking and reassuring, they may have misled the professionals.

Regardless of gender, most of the suicides were unexpected, violent, and well planned thus offering little chance for others to intervene. The decision to commit suicide was taken days or weeks beforehand, as evidenced by a change of behaviour and indirect verbal messages. Many of these teenagers were reported to have become calmer some time before the suicide, thus making others more hopeful and less vigilant, which adds to the pain of the consequences for the bereaved.

THE FAMILIES

The material did not allow a close account of the families, but many parents were reported to have turned down offers of professional help after the suicide. This may demonstrate a difficulty, shared with their children, in accepting external support when facing problems. However, the posthumous reputation may be unjust $^{9}$ and parents whose children commit suicide often have to face the added burden of societal blame. ${ }^{10}$ Notwithstanding, we found some support for parental neglect, albeit in only a few cases.

\section{THE COMMUNITIES}

Some suicides occurred in smaller towns and villages along the coast but the majority occurred in the interior parts of the region. Such geographical distortion implies that sociopolitical and cultural factors are important to consider.
Firstly, the northern region of Sweden, and particularly the interior parts, have, for decades, been drained of people, job opportunities, and community services. Young people have had to move to the larger cities along the coast for jobs and higher education and in the past years even this opportunity has diminished. One can postulate that those who do move are more often than not mentally robust and confident. Thus, the inner parts of the region may have accumulated people who are more passive and depressive. On the other hand, to resist moving is also an act of self confidence. It takes vitality, endurance, and creativity to manage living in an area of decline.

Secondly, in many interviews, we were given a rather pessimistic view of living in these communities. ${ }^{12}$ According to Wetzel et $a l,{ }^{11}$ hopelessness is of greater significance in suicide aetiology than depression, and young people are sensitive to the messages of the adult world.

Thirdly, the people of the region have traditionally been reluctant to seek advice for personal problems. This attitude, mostly confined to men, seems to be changing but the provision of social and mental health services are still better developed in the major cities.

\section{LIMITATIONS}

Even though the reliability of psychological autopsies is fairly good, ${ }^{12}$ a retrospective study, relying on indirect data, is subject to recall bias. However, we relied on multiple sources, covering the functioning of the teenagers over an extended period, and from different professional perspectives. Nevertheless, lack of uniformity in the data collection may have distorted the findings in unknown ways.

Our approach is a new way to capture important information that might otherwise be disregarded. Interviews with bereaved families on the one hand, and policemen and professionals on the other, yield different knowledge. Since the study included only a few cases, the results are also susceptible to sampling biases. However, we have compared our results with those of an earlier study that included 46 cases of suicide (L Johansson, A Eriksson, unpublished observations) and found that the present smaller study mirrors the larger sample in most respects.

\section{Implication for prevention}

One of the strongest risk factors in teenage suicide is a history of suicide attempts. ${ }^{13}$ Although only few of the suicide attempters do commit suicide later, a history of attempts, especially in the presence of a psychiatric disease, must be taken seriously, as shown in this study. Awareness of this fact must be implemented in the clinical work among pediatricians and psychiatrists.

However, because of low baseline rates of teenage suicide, it is exceedingly difficult to identify teenagers at risk. Therefore, we also believe that suicides should be analysed and prevented in a similar way as diseases and unintentional injuries are handled. Haddon's matrix ${ }^{14}$ that is, a systematic analysis of the pre-event, event, and the post-event phases, 
may serve as a useful approach in order to find preventive measures. The basic idea is to focus on interventions that target general conditions rather than to identify individuals at risk. Suicide prevention can, according to this scheme, include reduction of harmful agents in the environment, for example, firearms. ${ }^{15}$ Further, teenagers under the influence of alcohol are more likely to use violent and definitive methods. ${ }^{16}{ }^{17}$ Reduction of alcohol available for the teenage population could, thus, serve as another fruitful intervention.

In this study, as in Sweden as a whole, most cases of fatal poisoning by car exhausts involve the use of a vacuum cleaner tube. ${ }^{18}$ Making the exhaust pipes incompatible with the vacuum cleaner tube may also reduce the suicide rate as well as the installation of an automatic idling stop or a carbon monoxide sensor in all vehicles with an automatic engine stop at toxic levels. ${ }^{18}$ The idea is to win time to allow for the suicidal impulse to abate ${ }^{18}$ and to make it possible for others to intervene. Just as important, it is well established that the reduction of one suicide method is not compensated by an increase in the use of other methods. ${ }^{19}$

We are deeply indebted to Professor Anders Eriksson for his senior advice and to Ms Lolomai Örnehult who has patiently provided the study with indispensable secretarial support. The provided the study with indispensable secretarial support. The
study was funded by the Swedish Society of Medicine and First of May Flower Annual Campaign.

1 Calhoun LG, Selby JW, Faulstich ME. Reactions to the parents of the child suicide: a study of social impressions. $\mathcal{F}$ Consult Clin Psychol 1980;48:535-6.
2 Diekstra RFW, Gulbinat W. The epidemiology of suicidal Diekstra RFW, Gulbinat W. The epidemiology of suicidal behaviour: a revien

1993;46:52-68.
Hultén A, Wasserman D. Suicide among young people aged 10-29 in Sweden. Scand $\mathcal{F}$ Soc Med 1992;20:65-72.

4 Deavoll BJ, Mulder RT, Beautrais AL, et al. One hundred years of suicide in New Zealand. Acta Psychiatr Scand $1993 ; 87: 81-5$

5 Official Statistics of Sweden. Causes of death 1994. Stockholm: National Board of Health and Welfare, 1996: 148-50.

6 Beck AT, Schuyler D, Herman I. Development of suicidal intent scales. In: Beck AT, Resnick HLP, Lethieri DJ, eds. The prediction of suicide. Bowie, Maryland: Charles Press, 1974: 45-56.

7 Marttunen MJ, Aro HM, Henriksson MM, et al. Mental disorders in adolescent suicide: DSM-III-R axes I and II diagnoses in suicides among 13-to 19-year-olds in Finland. Arch Gen Psychiatry 1991;48:834-9.

8 Shaffer D, Gould MS, Fisher P, et al. Psychiatric diagnosis in child and adolescent suicide. Arch Gen Psychiatry 1996; 53:339-48.

9 Miles MS, Demi AS. A comparison of guilt in bereaved parents whose children died by suicide, accident, or chronic disease. Omega 1991/92;24:203-15.

10 Rudestam KE, Imbroll D. Societal reactions to a child's death by suicide. F Consult Clin Psychol 1983;51:461-2.

11 Wetzel KD, Margulies T, Davis R, et al. Hopelessness, depression, and suicide intent. F Clin Psychiatry 1980;41: $159-60$.

12 Beskow J, Runeson B, Åsgård U. Psychological autopsies: methods and ethics. Suicide Life Threat Behav 1990;20: 307-23.

13 Grossman DC. Risk and prevention of youth suicide. Pediatr Ann 1992;21:448-54.

14 Haddon W Jr. Options for the prevention of motor vehicle crash injury. Isr f Med Sci 1980;16:1.

15 Brent DA, Perper JA, Allman CJ, et al. The presence and accessibility of firearms in the homes of adolescent suicides. FAMA 1991;266:2989-95.

16 Crumley FE. Substance abuse and adolescent suicidal behavior. FAMA 1990;263:3051-6.

17 Brent DA, Perper JA, Allman CJ. Alcohol, firearms, and suicide among youth. $\mathscr{f} A M A$ 1987;257:3369-72.

18 Öström M, Thorson J, Eriksson A. Carbon monoxide suicide from car exhausts. Soc Sci Med 1996;42:447-51.

19 Kreitman N. The coal gas story. United Kingdom suicide rates, 1960-71. British fournal of Preventive and Social Medicine 1976;30:86-93.

\section{Student dies in PE class}

In February, the Melbourne newspaper, the Herald Sun, reported the case of a 12 year old girl who died on the school running track during a physical education class. Although the cause of death is not clear, the $32^{\circ} \mathrm{C}$ temperature may have been a contributory factor. What seems odd is that policy on whether or not to proceed with PE in such conditions rests with individual schools rather than the Education Department, comment regular Injury Prevention contributors Jan Shield and David Bass who spotted this report.

\section{8 die on South African roads}

South African roads have claimed 778 lives since 1 December. A statement from the Drive Alive Campaign said that the victims had died in 544 accidents. Of the fatalities, 352 were passengers, 222 pedestrians, and 204 drivers. The deaths on South African roads, among the world's most dangerous, have been blamed on recklessness and speeding drivers. Last year, 791 people were killed in road crashes in December (The Age (Melbourne), 3 January 2000). Contributed by fan Shield

\section{Three hours in hot car: boy in coma}

Homicide squad detectives have interviewed a woman after she left her 19 month old son unattended in a car for nearly three hours. The woman, in her 30s, left the toddler in the car park of a hotel while she was in the hotel's gaming room, police said. The temperature reached $33^{\circ}$. The police said that research has shown that the inside of the car could heat to $67^{\circ}$ within 15 minutes when the outside temperature was $36^{\circ}$. (The Age (Melbourne), February 2000). Contributed by fan Shield

Editor's note: Jan Shield reports that the child subsequently died. 